\title{
Durable polymer electrolyte fuel cells (PEFC) for residential co-generation application
}

\section{- Elucidation of degradation mechanism to establish an accelerated aging test method of PEFC -}

\author{
Kazumi TANIMOto*, Kazuaki YASUdA, Zyun SIROMA, Tomoki AKITA and Tetsuhiko KobAYASHI
}

[Translation from Synthesiology, Vol.5, No.1, p.53-61 (2012)]

\begin{abstract}
Co-generation system using clean and compact PEFC which makes highly efficient power generation possible, promotes considerable energy savings at home since it provides both heat and electricity together. Therefore, its commercialization has been expected. The goal of 40000-hour-operation has been set as a practical target. In order to realize it, the durability of PEFC has been technologically prospected and the accelerated aging test protocol of PEFC has been developed within the frame of the consortium of PEFC makers, energy companies, academia and AIST. AIST has shown the rationality of the accelerated aging test protocol of PEFC through the experimental verification of hypothetical degradation mechanism. The application of the developed accelerated aging tests to actual fuel cells has made it possible to get a clear view of practical durability, and this has led to the commercialization of residential PEFC co-generation.
\end{abstract}

Keywords : Polymer Electrolyte Fuel Cell, accelerated test protocol, degradation mechanism, co-generation system for resident

\section{Introduction (Background of research)}

The fuel cell power generation, in which the energy generated in the production of water in the electrochemical reaction of hydrogen and oxygen is used as electricity, is a technology where the chemical energy of a substance is directly converted into electric energy. It is not limited by the Carnot efficiency because it does not involve heat energy as in the heat engine, and high energy conversion efficency can be expected. Therefore, many researches have been conducted for its practical application. Since the fuel cell converts the energy of the chemical reaction between hydrogen and oxygen to electricity, the reaction progresses faster at higher reaction temperature, and this enables improvement in efficiency. Since the produced emission is water, it is clean and is highly environment friendly.

The fuel cell started from the gas reaction experiment conducted by Sir William Robert Grove of Britain in 1839 . As shown in Fig. 1, this experiment probably involved two platinum electrodes in dilute sulfuric acid solutions, where one electrode was filled with hydrogen gas and the other with oxygen gas. The electrodes were connected in series, and electrolysis was conducted by the generated electricity. The power generation using the electrochemical process did not advance far compared to the dramatic leap of the generation using the heat engines. However, the basic researches for the high-temperature fuel cell were conducted as one application of this technology to the generation method using coals combustion technology, the major fuel course of that time.
The fuel cell researches using the molten salts, oxides, and others as electrolytes were conducted in the early 20 th century. In 1921, the high-temperature fuel cell of $1.5 \mathrm{~kW}$ was demonstrated using molten carbonate as the electrolyte.

The basic configuration of the current fuel cell in which the porous structures of the cathode and anode are sandwiched between electrolytes was established in 1933 in the Bacon cell that used alkaline water solution as the electrolyte and nickel sintered compact as the electrode. The Bacon cell was significant in presenting a practical fuel cell configuration where the efficient electrode reactions were obtained at the

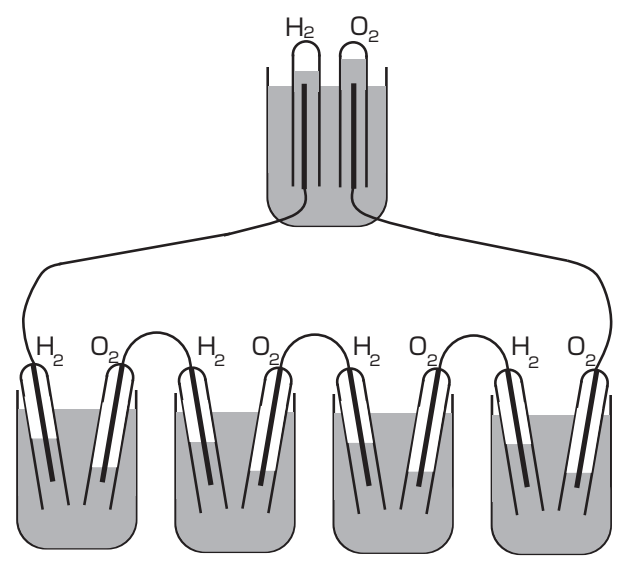

Fig. 1 Sir Grove's gas voltaic battery which was assembled of platinum electrodes in dilute sulfuric acid solution

The upper part is the electrolysis of water. Lower part is the fuel cell.

1. Research Institute for Ubiquitous Energy Devices, AIST 1-8-31 Midorigaoka, Ikeda 563-8577, Japan

* E-mail: tanimoto-k@aist.go.jp

Original manuscript received November 4, 2011, Revisions received December 8, 2011, Accepted December 14, 2011 
three-phase interface composed of gas as the fuel (hydrogen gas) or oxidant, liquid as the electrolyte, and a solid electrode, respectively. The Bacon cell, which achieved the basic design of the practical fuel cell, was put to actual use, although in a special circumstance, as the power generating device for the spacecraft in the American space program. Later, the alkaline fuel cell was installed as the power source of the space shuttle.

On the other hand, the fuel cell used in the actual spacecraft Gemini 5 in 1965 was the type in which the cation exchange membrane was used as the electrolyte, rather than the alkaline type. This fuel cell used pure hydrogen and pure oxygen that were the propellant of the spacecraft. Later, as mentioned earlier, the alkaline type became the mainstream for space use. On the other hand, DuPont developed Nafion, the fluorocarbon cation exchange membrane, and the performance increased greatly. In the 1970s, the development of the fuel cell power system was started as the next generation power generation technology. As the power generation technology, it was preferable to use air as the oxidizing gas due to its simplicity as a system. However, air contains carbon dioxide, and in the fuel cell that uses alkaline solution as the electrolyte, there was the issue of decreased performance due to the production and accumulation of unsolved carbonate salt in the electrolyte. Moreover, the fuel gas of the fuel cell power technology contains carbon dioxide because the hydrogen gas as fuel is produced from hydrocarbon. Therefore, in the development of the fuel cell power technology, it was necessary to add a device for removing the carbon dioxide or to use acid electrolyte. Therefore, both the developments of the fuel cell using alkaline and the one using acid, for example, phosphoric acid were conducted in parallel. Later, from the standpoint of long-term performance stability, the development of phosphoric acid fuel cell progressed. Today, it is developed as the distributed generation system of about $100 \mathrm{~kW}$ with lifespan of about 60,000 hours. In terms of system cost, it is competitive as the distributed power generation technology. During the Great East Japan Earthquake, it was used as the alternative power generation system during the blackouts, ${ }^{\text {Note 1) }}$ and its durability and cost are the issues for practical application.

After the development of the Nafion membrane, the nanotechnology to reduce the amount of platinum in the catalyst to a few fractions was developed in the late 1980s, by utilizing the platinum surface efficiently as a catalyst, by mixing the platinum supported carbon and the cation exchange resin electrolytes. This kicked off the development of the polymer electrolyte fuel cell (PEFC) for power generation in Japan as well as the United States and Europe in the 1990s. The developments were planned for distributed cogeneration and automobile application. Although there is a long history of development of the fuel cell, the cases of its practical application are limited. For its product realization, there are research efforts necessary in the phases from basic research, development, and commercialization. AIST engages in Full Research that engages systematically from basic research to product realization. Here, we present the efforts in Full Research using the example of the fuel cell.

\section{For the practical application of fuel cells}

The fuel cell is a power generation device that produces electricity by the electrochemical reaction of hydrogen and oxygen. It is a component of the product used by the end user. Therefore, the fuel cell itself is not the product. For example, considering the product such as the fuel cell automobile, the fuel cell is the engine that propels the automobile, and whether the end user buys this product depends on his/her thinking on the value of the fuel cell automobile. While the fact that the automobile has an efficient power generation system that is clean and environment friendly, which are the characteristics of the fuel cell, as the engine may enhance the value of the fuel cell automobile, the value of an automobile is determined by the combination of driving performance, fuel-savings, and price. In conducting the fuel cell technology development for practical application, the issues of performance, cost, and durability were handled one by one. This arose from the fact that the fuel cell technology was in the technological budding stage where the three issues could not be solved at once. Therefore, it could not get out of the R\&D stage. At the same time, this indicated that the fuel cell technology was always the technology of the future against the competing technologies such as the internal combustion engine and secondary batteries. This was not just a problem of fuel cell technology. In the basic research phase of many next-generation technologies, the simultaneous achievement of the solutions that must be solved for practical application is difficult, and the research must concentrate on one issue at a time. Therefore, as the development of the solution to one issue is sought, other technological issues are left behind in terms of practical application. This is a difficulty that faces the researchers conducting the R\&D.

In the fuel cell technology, attempt was made to overcome this issue by downsizing the fuel cell in the product to lower the hurdle of technological issues, yet not detracting from the value as a product. While this method may not be effective for all products, there seemed to be opportunities for trials due to the demand of the social situation or due to the marketability of the product. The residential cogeneration system that incorporated PEFC as the generation device could be used in the residential cogeneration where the exhaust water used for cooling the heat produced along with the electricity generated by PEFC at around $70{ }^{\circ} \mathrm{C}$ could be used as hot water. This was expected to be the product with the role in global warming countermeasure through energy saving and reduction of $\mathrm{CO}_{2}$ emission at home. In fact, there was a preceding case where the residential cogeneration 
system with the gas engine was commercialized and became wide spread in 2003. The generation efficiency of the gas engine was over $20 \%$, and it was heat-main electricity-sub supply where the main supply would be heat rather than electricity. As the energy utility form at home, the percentage of electric appliances increased, and considering the hot and humid climate in Japan, it was thought that electricitymain heat-sub supply where the percentage of electricity supply was higher would have higher demand. Therefore, high electric power generation efficiency was required in the cogeneration devices. As the generation efficiency of PEFC was expected to surpass $30 \%$, the potential for the marketability of residential fuel cell cogeneration system was expected to be high. In fact, accompanying the continuous progress in the R\&D for PEFC after the $1990 \mathrm{~s}$, the generation efficiency was in the $30 \%$ level performance and the conditions for commercialization were being fulfilled. However, the durability of the product was insufficient compared to the competing technologies, and the technological development to maintain the durability for withstanding practical use was necessary.

In this situation, in 2004, the government policy was set to introduce the residential fuel cell cogeneration to expand the use of fuel cells by 2008 . The demonstration of PEFC residential cogeneration system started in 2005, and at the same time, R\&Ds were conducted for increasing the durability that was necessary for commercialization. The goal for durability of the PEFC in its initial commercialization stage was set at 40,000 hours considering the social acceptability and system cost. Figure 2 shows the thinking of the development in the background of the social shift to low carbon energy society, where the downsized fuel cells would lower the hurdle of technological issues against the competing technologies, and the focus on durability as the development issue for residential cogeneration would enhance commercialization.

The technological development of improved durability was also essential for the automotive and mobile power system uses in which the PEFC technology could be used. In automotive use, the severe usage environment, rapid output shift for the power source device, start-up in a short time, and others were expected, and in practical use, the actual operating time would be shorter than the idle time. Such difference in operating conditions may require different measures when making technological estimates for obtaining durability. However, there is no major difference in the PEFC material configuration, and the findings on degradation phenomenon and mechanism obtained in the investigation for residential cogeneration system can be applied.

\section{Objective and necessity of accelerated aging method of PEFC}

The development of PEFC technology in Japan was started as the national project and by fuel cell system manufacturers in the early $1990 \mathrm{~s}$. Therefore, the system manufacturers accumulated unique technologies for the PEFC material, configuration, and system. As mentioned earlier, around 2004 the direction for the commercialization in 2008 of the fuel cell residential cogeneration was given to promote energy savings and as a measure against global warning. While the companies were aware of the common technological issues for obtaining the 40,000-hour durability, the exchange of technological information did not occur. Particularly, the degradation phenomenon that was the issue in practical use was unclear, although it was expected that the operating condition of PEFC would affect the material, performance, and cell structure.

As part of the establishment of technology pertaining to the durability for the commercialization of PEFC in 2008, the 3.5 year NEDO Project "Fundamental Research of Degradation of PEFC Stacks" was started in October 2004 , in the industry-academia-government collaborative consortium consisting of the system maker, energy supplier, universities, and AIST. While 40,000-hours-operation were required as the durability of the fuel cell that would be the main body of the fuel cell residential cogeneration system, the lifetime of PEFC stack in 2005 was about 10,000 hours, and the technology to dramatically increase the durability was necessary. To clarify the common degradation issue for which the fuel cell system makers possessed unique technological information, the makers set the goal of developing the accelerated test protocol for the fuel cells. The project was executed under the scheme of clarifying the degradation phenomenon and mechanism. Since 40,000 hours was about 4.6 years in actual time, the development of the accelerated test to predict the 40,000-hour durability in a year was meaningful to the companies. At the same time, since the accelerated test protocol would be explained by the degradation mechanism, the investigation of degradation

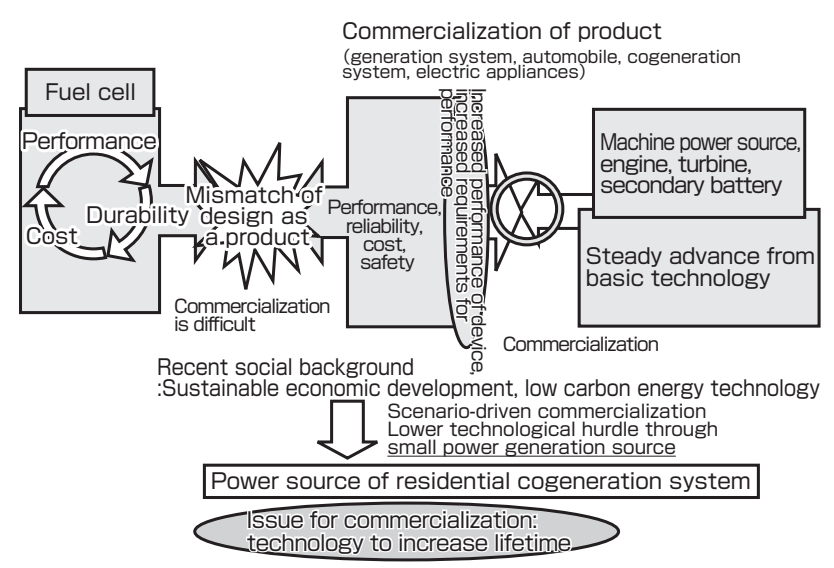

Fig. 2 Past processes of the fuel cell development and the development toward commercialization 
factors would progress. In the actual project, the confirmation of 40,000-hour lifetime by the accelerated test was not the only objective, but the clarification of the degradation factors was an important issue of PEFC development.

In this project, to establish the technology for practical accelerated tests for the fuel cell cogeneration system expected to be commercialized in 2008 , the accelerated test to estimate the use of 40,000 hours in one year was developed. Led by the energy supply companies that were close to the end users, roundtable discussions were held among the energy supply companies and the fuel cell system maker on the issues pertaining to the PEFC degradation in the fuel cell cogeneration system. The priority issues for the PEFC degradation were extracted, and the objectives were set to clarify the degradation mechanism and to develop the accelerated test method. ${ }^{[1]}$

\section{Investigation of the degradation mechanism}

\subsection{Degradation factors of the actual cell/stack and the accelerated aging method}

Figure 3 shows the data for the time profile of the cell performance that the participating members possessed at the start of the project. The degradation due to the decreased cell performance were categorized into four patterns and investigated.

In the accelerated degradation pattern of (c) the constant output is continued in normal operation, but the folding point cannot be estimated. It was judged to be most fatal for the cogeneration system because the standard output would no longer be obtained immediately after the folding point. In the linear performance decline of (a), the end life can be estimated from the rate of voltage decrease. If this period is

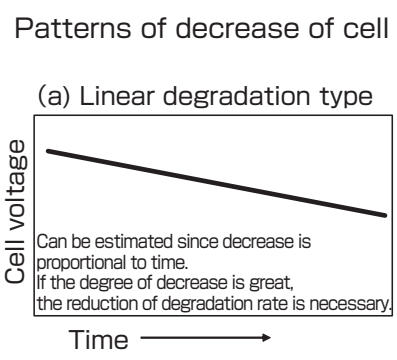

(b) Saturated degradation type

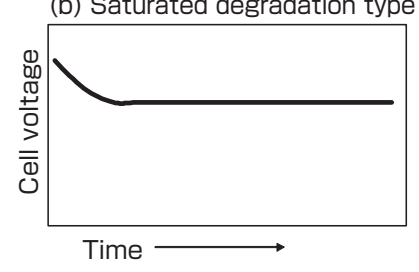

Fig. 3 Types of degradation behavior in the time change pattern of cell property faster than 40,000 hours, it must be controlled. For pattern (d), it was determined that this is caused by the problems in the management of cell manufacture or the failure in system configuration. Based on the above patterns, and considering the time profile data of the cell performance of the system makers and the information pertaining to the cell material degradation, it was determined that the most important point was to cover the following three requirements, and priority should be given on solving them as well as clarifying the mechanism. The three requirements were: 1) to obtain the accelerated degradation pattern of (c); 2) considering the case of 40,000 hour durability with no saturation in the decrease of cell voltage, the effect is fatal; and 3) at this point, the evaluation method of degradation and countermeasures are not clear. The "decline of CO poisoning resistance" and the "decrease of gas diffusion due to the flooding at the electrode" shown in Fig. 4 were selected as main topics for the practical degradation factors, and were shared commonly as main topics among the members.

As the test protocol to accelerate the degradation factor, we proposed the introduced gas switching method. This test involved the two techniques: 1) the method of introducing air and nitrogen (inactive atmosphere) alternatively to the cathode (air electrode) of PEFC (method 1); and 2) the method of repeating the cycle of hydrogen $\rightarrow$ nitrogen $\rightarrow$ air $\rightarrow$ nitrogen $\rightarrow$ (hydrogen) to the anode (fuel electrode) of PEFC (method 2). In both methods, it was predicted that the surface of the supported carbon of the cathode catalyst layer would become oxidized by the retention of high potential at the cathode, flooding by water accumulated on the catalyst surface would progress, and gas diffusion at the electrode would decrease. For the establishment of the accelerated test protocol, the clarification of the corrosion reaction mechanism and the carbon corrosion behavior at the material surface was important.

For the "decrease of $\mathrm{CO}$ poisoning resistance of the catalyst at the fuel electrode" that was the other degradation factor, we considered including this as the accelerating condition. However, in the actual system, it was confirmed that the effect was seen when the CO concentration in the fuel gas was at several $10 \mathrm{ppm}$ level. It was determined that a practical accelerated test would not be possible unless the factors that caused the $\mathrm{CO}$ poisoning could be controlled with high accuracy, and it was also determined that it was not appropriate to conduct the accelerated test on the base of this factor. Since this phenomenon occurred as a result, it could be used as the index for determining the degree of degradation. In the actual PEFC anode catalyst, normally, to add resistance to $\mathrm{CO}$ poisoning, the alloy of platinum (Pt) and ruthenium $(\mathrm{Ru})$ is used instead of the Pt catalyst that is readily poisoned. However, the decrease of $\mathrm{CO}$ poisoning resistance occurs with this alloy catalyst, and it is thought to occur as the $\mathrm{Ru}$ dissolute from the anode catalyst in long- 
term operations. Also, the behavior of platinum in the alloy catalyst may be related to the durability.

\subsection{Degradation observation of the real cell}

To observe the fine structure of the real cell to which the aging test was done at micro level, the structural observation of the electrode catalysts was done using the transmission electron microscope (TEM). In the TEM observation, the first issue was to fabricate a sample that could be observed under TEM from the real cell subject to the aging test. The cell with which the generation test was done in the simulated aging condition was disassembled, and the thin EM sample slice of the membrane-electrode assembly (MEA) was made using an ultra microtome. Using this method, the structures of the electrode catalyst and the electrolyte membrane could be preserved and observed. Observations were done for the samples subject to the aging tests under various conditions including lack of fuel, potential flux cycle, and high potential. ${ }^{[2]-[4]}$ From the measurement of the particle size distribution under TEM observation, it was found that the size of the electrode catalyst particle increased, the composition of the $\mathrm{Pt}-\mathrm{Ru}$ fine particle changed ${ }^{[2]}$ as the $\mathrm{Ru}$ eluted from the anode $\mathrm{Pt}-\mathrm{Ru} / \mathrm{C}$ catalyst as seen by energy dispersive X-ray spectroscopy (EDS), and the phenomenon occurred where the metal particles of the electrode catalyst precipitated into the electrolyte membrane depending on the test condition, as shown in Fig. 5. For the particles that precipitated into the electrolyte membrane, it was found that the particle size distribution and the spatial distribution and precipitated particles changed by the influence of the type of gas supplied to the anode and cathode and by the thickness of the electrolyte membrane. ${ }^{[4]}$ Figures $5 \mathrm{a}$ and $5 \mathrm{~b}$ are the TEM images of the surrounding area of the cathode when the cathode potential was retained at $1.0 \mathrm{~V}$, nitrogen gas was supplied, and the electrolyte membranes with thickness $50 \mu \mathrm{m}$ (Fig. 5a) and $175 \mu \mathrm{m}$ (Fig. 5b) were used. The lower part of the photo is the $\mathrm{Pt} / \mathrm{C}$ catalyst layer. In the case of the thin electrolyte membrane, many particles were precipitated near the $\mathrm{Pt} / \mathrm{C}$ catalysts layer. When air was supplied to the cathode (Fig. 5c and $5 \mathrm{~d}$ ), the precipitated particles were distributed to areas further from the catalyst layer compared to when nitrogen was supplied. It was thought that the concentration inside the membrane of the hydrogen that permeated the membrane from the anode affected the precipitation distribution of the platinum particle in the membrane. In the EM observation, as shown in Fig. 5, the structural assessment of the electrode catalyst fine particles from $\mu \mathrm{m}$ to several $\mathrm{nm}$ is possible. The effectiveness of the fine structural analysis in practical materials such as PEFC was demonstrated. As the advancement of the recent EM technology is dramatic, the observation of a single atom of $\mathrm{Pt}$ is possible, and we think detailed data on the electrode catalyst structure can be obtained. With the improvement of the spatial resolution of EM, it is becoming possible to study the details of the electron state of carbon with the increased sensitivity of electron energy loss spectroscopy (EELS). Detailed information can be obtained for the carbon degradation of the cathode catalyst.

\subsection{Clarification of the degradation mechanism in a model cell}

While it was known through experience that the startstop operation of PEFC enhanced degradation, in 2005, an American researcher proposed the theory that the degradation occurred due to the "reverse current decay mechanism.. ${ }^{[5]}$ This theory states that when the fuel supply

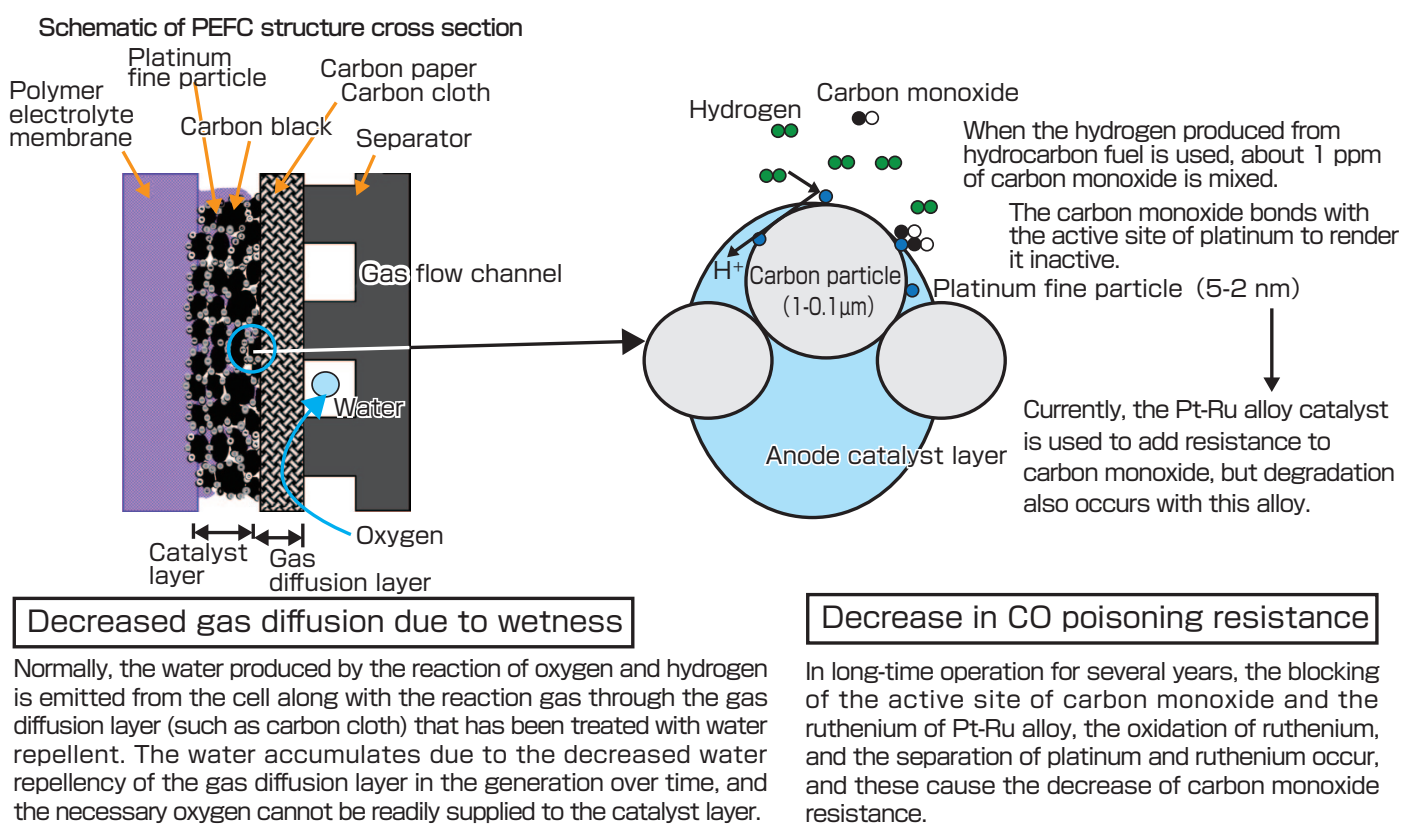

Fig. 4 Two issues on which weight must be placed for stack degradation

Two issues important in the degradation mechanism related to the decrease of cell performance are extracted based on the generation data of the companies participating in the project. 
is started when the air is remaining in the anode, a transient state appears where the region with fuel and the region with oxygen exist simultaneously within a cell, the reverse current is produced in some areas with remaining oxygen, and the electrode material carbon becomes corroded as the potential of the cathode becomes high in some areas. Since such phenomenon could not be measured by observing the cell from the outside, to verify the "reverse current decay mechanism," we conducted measurements by fabricating the "100 segment cell" (Fig. 6). The electrode was divided into minute segments, settings were done to measure the time change of the generated current distribution and the local potential distribution within a cell, and transient states were created by switching several types of gases. As a result, we succeeded in measuring the abnormal high potential of about $1.6 \mathrm{~V}$ locally (in normal operation, the material will not be subject to potential higher than $1 \mathrm{~V}$ ) in the transient state in which the "reverse current decay mechanism" was expected to occur. ${ }^{[6]}$ From the measurements of other types of transient states, we found two phenomena that were closely related to the conditions of the proposed accelerated aging test. One was the phenomenon in which the high potential that may cause cathode degradation like the "reverse current decay mechanism" could occur when the anode gas was switched from nitrogen to fuel. Another phenomenon was when the cathode was switched from nitrogen to air, certain anode had high local potential (about $0.7 \mathrm{~V}$ ) in the potential range of $1 \mathrm{~V}$ or less. These results offered logical explanation for the phenomena that occurred in the "accelerated aging method 2 " and "accelerated aging method 1" respectively. The phenomenon in which the anode local potential increased, for example, to $0.7 \mathrm{~V}$ in the cathode gas switching test was certainly a degradation factor as the ruthenium in the anode catalyst eluted. However, it was considered harmless for the carbon material since it was $1 \mathrm{~V}$ or less. However, when a basic test using beaker cells was conducted for the purpose

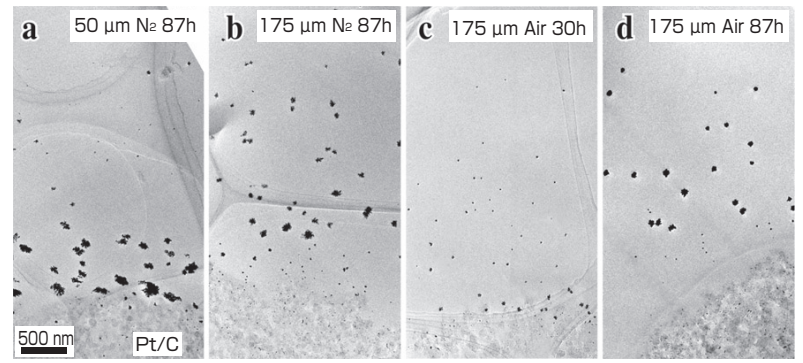

Fig. 5 TEM images of the Pt/C electrode catalyst layer and the electrolyte membrane interface after conducting the aging test by applying constant voltage (a) Using the $50 \mu \mathrm{m}$ electrolyte membrane, nitrogen was supplied to the cathode and $1.0 \mathrm{~V}$ was applied for 87 hours. (b) Using the $175 \mu \mathrm{m}$ electrolyte membrane, nitrogen was supplied to the cathode and $1.0 \mathrm{~V}$ was applied for 87 hours. (c) Using the $175 \mu \mathrm{m}$ electrolyte membrane, air was supplied to the cathode and $1.0 \mathrm{~V}$ was applied for 30 hours. (d) Using the $175 \mu \mathrm{m}$ electrolyte membrane, air was supplied to the cathode and $1.0 \mathrm{~V}$ was applied for 87 hours. of studying the factors that affected the rate of carbon corrosion, it was found that the change in potential was the factor that promoted carbon corrosion even in the range of $1 \mathrm{~V}$ or less that was thought to not cause much corrosion. ${ }^{[7]}$ Combining these findings, it was found that the degradation in the "accelerated aging method 1" accelerated not only the ruthenium elution but also the carbon corrosion.

In the PEFC cathode, the surface area of the effective platinum catalysis decreased with degradation, and this was because of the increased particle size and loss of platinum due to dissolving, as well as the shedding and aggregation due to the corrosion of the supported carbon. To investigate these phenomena, we devised the "identical position observation" that allowed almost "in-site observation." Microscopic observation (AFM and SEM) of the shedding and aggregation of the platinum particles on the model electrode was conducted, and the phenomenon where the presence of platinum promoted the carbon corrosion was captured ${ }^{[8][9]}$ These results made basic contributions in accurately understanding the degradation phenomena that occurred under the accelerated aging condition.

\section{From the development of accelerated aging method to commercialization}

As the test method for accelerating the degradation process by enhancing the "decrease of gas diffusion by the flooding at the electrode," we proposed two gas switching methods. The phenomenon of flooding due to increasing the wettability of the cathode was hypothesized as being caused by the production of hydrophilic functional group at the surface of the catalyst support carbon. For the production of this hydrophilic group, the carbon oxidation would not be enhanced greatly even if open voltage $1 \mathrm{~V}$ was retained, but such functional group might be yielded by shifting the potential by switching

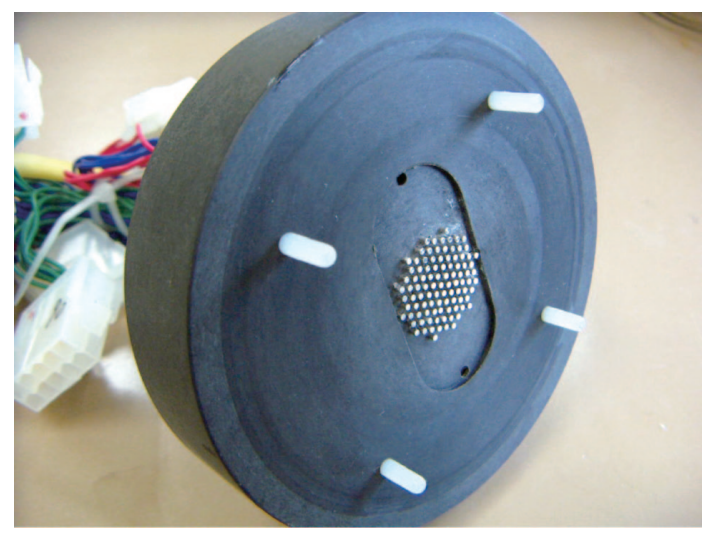

Fig. 6 External appearance of the segmented electrode of the "100 segment cell" fabricated to measure partial current and local potential 
Table 1. Introduction of ENE-FARM by subsidy

\begin{tabular}{|c|c|c|c|}
\hline & City gas type/ unit & LP gas type/ unit & Total / unit \\
\hline FY 2009 & 3,681 & 1,349 & 5,030 \\
\hline FY 2010 & 3,969 & 1,016 & 4,985 \\
\hline FY 2011 & 10,526 & 1,911 & 12,437 \\
\hline Total & 18,176 & 4,276 & 22,452 \\
\hline
\end{tabular}

(For FY 2011 , the number is for the application received by December 27, 2011)

the cathode or anode gases. Also, high potential of about $1.6 \mathrm{~V}$ could be induced depending on the condition of gas switching according to the model cell experiment, and this could offer the rationale for the accelerated test protocol by gas switching. The decrease of gas diffusion in the catalyst layer was thought to arise from the electrochemical reaction of the catalyst supported carbon. The dissolution of ruthenium of the anode catalyst was confirmed in the analysis and observation of the electrolyte membrane and the electrode catalyst layer after cell operation. These behaviors were thought to decrease the CO poisoning resistance of the Pt-Ru alloy catalyst over time. The increase of anode potential was confirmed in the anode gas switching condition. It was thought that such aging condition would not occur under normal operation, but since the local distribution of the gas composition caused the potential increase, the dissolution of ruthenium of the anode catalyst was accelerated.

The PEFC residential cogeneration system uses the fuel cell of about $1 \mathrm{~kW}$ as the power source. The durability was evaluated by applying the accelerated test protocol to this fuel cell by gas switching method. As a result, for the fuel cells of the various fuel cell system manufacturers, about seven-fold acceleration rate was obtained in the cathode gas switching method, and about 100-fold acceleration effect was observed for the anode gas switching method. In this project, the companies that manufactured the PEFC residential cogeneration system were able to confirm the 40,000-hour durability through the accelerated test, and the commercialization in market was initiated. As part of the attempt to spread the PEFC residential cogeneration system, the energy supplier and the fuel cell system makers gave the name "ENE-FARM" to this commercialized product system. This name is a combination of energy and farm. The ENEFARM was commercialized in May 2009, and it is spreading all over Japan as shown in Table 1.

\section{Conclusion}

For the authors who have been engaging in research of the fuel cells as the next-generation technology, the fact that the fuel cell, which was always called the technology of the coming generation, became commercialized as ENE-FARM was a satisfactory event. The factors that allowed the fuel cell to become commercialized were that the initial stage of the residential cogeneration market was formed as society became increasingly eco-minded, and that there was excellent generation efficiency of the fuel cell compared to the gas engine technology that has already been in this market. Since the electricity-main heat-sub tendency was increasing in the home energy consumption, the generation efficiency was highly adaptable in terms of the balance of electricity and heat with electricity being main. The fuel cell cogeneration system is clearly adaptable as a commercial product compared to the gas engine cogeneration. Also, the interest in reducing the emission of carbon dioxide, preparing against disaster and saving energy accelerated the formation of the residential cogeneration market. The technology development in the industry-academia-government collaboration was important in the commercialization of the ENE-FARM. For a product that was so close to commercialization, there was very little incentive on the part of the companies to engage in joint technological development while sharing the unique corporate information. In this case, vertical collaboration with the energy supply companies was done aiming for the new market formation for residential cogeneration. AIST managed the unique technological information, the sharing of developed information progressed, and the positive incentives such as lowered risk of R\&D functioned well.

Currently, the ENE-FARM is spread widely due to government's subsidies. For autonomic market growth, further decreased cost and increased reliability and durability are necessary. To do so, research and development must be conducted from the designing aspect of residential cogeneration system by the fuel cell system makers, and at the same time, it is necessary to engage in researches to increase the performance and durability of the PEFC as well as to decrease the cost. AIST wishes to contribute as much as possible.

\section{Acknowledgement}

The industry-academia-government collaboration project "Fundamental Research of Degradation of PEFC Stacks" was conducted from October 2004 to March 2008, under the subcontract by New Energy and Industrial Technology Development Organization (NEDO). We are thankful to the people involved. We also express our thanks to the following participants of the project: Toshiba Fuel Cell Power Systems Corporation, Sanyo Electric Co., Ltd. (now part of Panasonic Corporation), Matsushita Electric Industrial Co., Ltd. (now Panasonic Corporation), Tokyo Gas Co., Ltd., Osaka Gas Co., Ltd., Nippon Oil Corporation, Kyoto University, Yokohama National University, and Doshisha University.

\section{Note}

Note 1) http://www.fujielectric.co.jp/about/news/11041101/ index.html 


\section{References}

[1] NEDO Report "Heisei 17 Nendo Heisei 19 Nendo Seika Hokokusho Kotaikobunshigata Nenryodenchi Jitsuyokasenryakuteki-gijutsukaihatsu; Kisoteki Kyotsuteki Kadai Ni Kansuru Gijutsukaihatu; KotaikobunshigataNenryodenchi Sutakku No Rekka Kaiseki Kiban Kenkyu 'Sutakku Rekka Mekanizumu Kaimei Ni Kanshite No Kisoteki-shien Kenkyu"' (Fiscal Year 2005 2007 Final Report: Strategic Development of PEFC Techonologies for Practical Application; Development of Technologies on Basic and Common Issues; Fundamental Research of Degradation of Polymer Electrolyte Fuel Cell Stacks [Basic Support Research on the Clarification of Stack Degradation Mechanism]) No. 100012431. Can be downloaded from NEDO homepage (in Japanese).

[2] A. Taniguchi, T. Akita, K. Yasuda and Y. Miyazaki: Analysis of electrocatalyst degradation in PEMFC caused by cell reversal during fuel starvation, J. Power Sources $130,42-49$ (2004).

[3] K. Yasuda, A. Taniguchi, T. Akita, T. Ioroi and Z. Siroma: Platinum dissolution and deposition in the polymer electrolyte membrane of a PEM fuel cell as studied by potential cycling, Phys. Chem. Chem. Phys., 8, 746-752 (2006).

[4] T. Akita, A. Taniguchi, J. Maekawa, Z. Siroma, K. Tanaka, M. Kohyama and K. Yasuda: Analytical TEM study of Pt particle deposition in the proton-exchange membrane of a membrane- electrode-assembly, J. Power Sources 159, 461467 (2006).

[5] C. A. Reiser, L. Bregoli, T. W. Patterson, J. S. Yi, J. D. Yang, M. L. Perry and T. D. Jarvi: A reverse-current decay mechanism for fuel cells, Electrochem. Solid-State Lett., 8, A273-A276 (2005).

[6] Z. Siroma, N. Fujiwara, T. Ioroi, S. Yamazaki, H. Senoh, K. Yasuda and K. Tanimoto: Transient phenomena in a PEMFC during the start-up of gas feeding observed with a 97-fold segmented cell, J. Power Sources, 172, 155 -162 (2007).

[7] Z. Siroma, M. Tanaka, K. Yasuda, K. Taninoto, M. Inaba and A. Tasaka: Electrochemical corrosion of carbon materials in an aqueous acid solution, Electrochemistry, 75, 258-260 (2007).

[8] Z. Siroma, K. Ishii, K. Yasuda, Y. Miyazaki, M. Inaba and A. Tasaka: Imaging of highly oriented pyrolytic graphite corrosion accelerated by $\mathrm{Pt}$ particles, Electrochem. Commun., 7, 1153-1156 (2005).

[9] Z. Siroma, K. Ishii, K. Yasuda, M. Inaba and A. Tasaka: Stability of platinum particles on a carbon substrate investigated by atomic force microscopy and scanning electron microscopy, J. Power Sources, 171, 524-529 (2007).

\section{Authors}

\section{Kazumi TANIMOTO}

Joined the Osaka National Research Institute, Agency of Industrial Science and Technology in 1984. Head of the Collaborative Research Team for Molten Carbonate Fuel Cell, AIST Kansai Collaboration Center, Collaboration Promotion Department in 2001. Deputy Director of the Research Institute for
Ubiquitous Energy Devices, and leader of the Fuel Cell Durability Research Group in 2004. Currently, leader of the Ionics Research Group. Achieved the 40,000-hour continuous generation using the MCFC (Molten Carbonate Fuel Cell) in 1995, and engaged in the material research for MCFC to improve durability. From 2004 to 2007, was in charge of organizing the Project for Fundamental Research of Degradation of PEFC Stacks presented in this paper.

\section{Kazuaki YASUDA}

Joined the Osaka National Research Institute, Agency of Industrial Science and Technology in 1994. Advanced Fuel Cell Research Group, Special Division for Green Life Technology, AIST in 2001. Leader of the Advanced Fuel Cell Research Group, Research Institute for Ubiquitous Energy Devices in 2004. Currently, Director of the Research

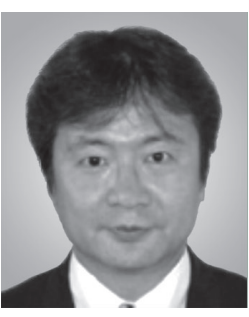
Planning Office of Environment and Energy. Since joining AIST, has engaged in basic research on the polymer membrane of fuel cells. Prior to the Project for Fundamental Research of Degradation of PEFC Stacks presented in this paper, engaged in the basic research for degradation in the industry-academiagovernment collaborative project for clarifying the PEFC degradation factors from 2001, and proposed the topics in practical use based on this experience.

\section{Zyun SIROMA}

Completed the master's program at the Graduate School of Engineering, Kyoto University in 1996. Joined the Osaka National Research Institute, Agency of Industrial Science and Technology in 1996. Engaged in research for the assessment of material and cell using electrochemical methods to clarify the degradation factors and to improve

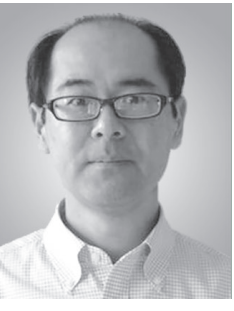
the performance of PEFC. Received doctorate in 2008 (Engineering, Kyoto University). Currently, Senior Researcher of the Advanced Fuel Cell Research Group, Research Institute for Ubiquitous Energy Devices, AIST. In this paper, was in charge of the clarification of the degradation mechanism using the model cell.

\section{Tomoki AKITA}

Completed the doctoral program at the Department of Applied Physics, Graduate School of Engineering, Osaka University in 1998 (Doctor, Engineering). Special Researcher at the Osaka National Research Institute in 1998; joined the Osaka National Research Institute in 1999. Nano Interface Function Research Group, Special Division for Green Life

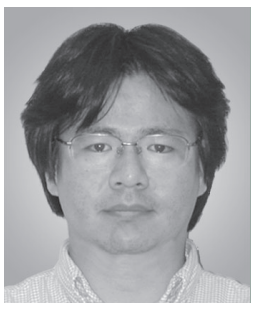
Technology, AIST in 2001. Senior Researcher of the Nano Material Science Research Group, Research Institute for Ubiquitous Energy Devices, AIST in 2004. Engages in the structural analysis of functional materials using the analytic electron microscope. In this paper, was in charge of analyzing the degradation of the fuel cell material using EM. 


\section{Tetsuhiko KoBAYASHI}

Joined the Osaka National Research Institute, Agency of Industrial Science and Technology in 1984. Director of the Special Division for Green Life Technology, AIST in 2001. Director of the Research Institute for Ubiquitous Energy Devices, AIST in 2004. At the commencement of the Project for Fundamental Research of Degradation

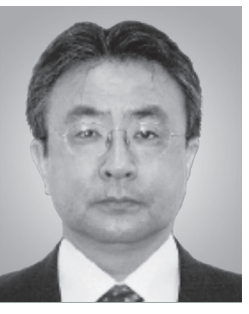
of PEFC Stacks described in this paper, was the research liaison for various organizations including the Ministry of Economics, Trade and industry, NEDO, fuel cell system companies, energy supply companies, and universities.

\section{Discussion with Reviewers}

1 Difference between "product" and "commercial product" Question (Kazuo Igarashi, Institute of National Colleges of Technology, Japan)

In the text, you use the two terms "product" and "commercial product." There are places where you make the distinction between the two and places where you don't. I think it is important to separate the two, so please review the use of these terms.

Answer (Kazumi Tanimoto)

In this paper, the "product" is the device that incorporates the fuel cell such as the fuel cell cogeneration system and fuel cell automobile. "Commercial product" is the product that has been commercialized such as the residential cogeneration system "ENE-FARM." When the "product" is commercialized, the cost is added to the functions such as performance and durability to be acceptable in society, and this becomes the "commercial product."

As you indicated, there were two places in "Chapter 6 Conclusion" where the terms were interchanged, and this was corrected.

\section{Molten carbonate fuel cell (MCFC)}

\section{Question (Kazuo Igarashi)}

In paragraph 2 , chapter 2 , you write "... there seemed to be opportunities for trials ... due to the characteristic of the product." What do you mean by this trial?

Answer (Kazumi Tanimoto)

This was a reference to the molten carbonate fuel cell (MCFC) that is one of the distributed fuel cell generation technology. In Japan, the Marubeni Corporation attempted to market the technology developed by FuelCell Energy of the USA as a distributed generation system. Marubeni established the Nihon Nenryo Denchi Hatsuden K.K. and conducted several demonstration tests, but the venture company was terminated in December 2011 and it was never launched in Japan. I regret this course of event, because I was involved in this technological development for 20 years. I think it has superior performance compared to other fuel cells. The demonstration trials are done in other countries as part of the investigation of the process for its commercialization. I added this description since I hope for the revival of this technology.

\section{Degradation pattern of the polymer electrolyte fuel cell (PEFC) \\ Question (Kazuo Igarashi)}

In paragraph 1 , subchapter 4.1 , you write, "the accelerated degradation pattern of (c) ... was determined to be most fatal for the cogeneration system." Can you describe in detail why you say so? Answer (Kazumi Tanimoto)

This is based on the empirical data of the manufacturers and the energy companies. The individual system designs are different in terms of the flexibility and adaptability of the system control in the cogeneration units. Fatal degradation is judged on the degree of damage.

\section{Scenario toward the practical use of fuel cell} Question (Norimitsu Murayama, Advanced Manufacturing Research Institute, AIST)

You write at the beginning of paragraph 2, "Chapter 2 For the practical application of fuel cell," "in the fuel cell technology... lower the hurdle of technological issues...." Specifically, what were the technological issues and how were the hurdles lowered? Answer (Kazumi Tanimoto)

One of the technological issues for the fuel cells was to scale up when it was introduced as the distributed power source. There is the issue of cost due to scale up. Scaling up the assemblies also brings new processing development for manufacturing components and unifying systems. For the application to small sized cells, the manufacturing technology will be an extension of the laboratory level, and I used the expression "lowering the hurdle" in that sense.

\section{Degradation mechanism of the polymer electrolyte fuel cell}

Question(Norimitsu Murayama)

Isn't it more straightforward if you say that the "decrease of gas diffusion by enhanced flooding at the electrode" and the "decrease of CO poisoning resistance" are accelerated by the gas switching method? Assuming this statement, in paragraph 3, "Subchapter 4.1 Degradation factors of the actual cell/stack and the accelerated aging method," I think you should explain the mechanism by which the $\mathrm{CO}$ poisoning resistance decreases by the gas switching test.

Answer (Kazumi Tanimoto)

In the project, the two factors of degradation were selected and investigated, and as described in the text, we were unable to sufficiently control the factor that accelerated the "decrease in CO poisoning resistance." As you indicated, if the two factors are presented in this text, I should follow them logically, but I write from the perspective of showing the efforts and processes of the research method. Also, seeing the "decrease of $\mathrm{CO}$ poisoning resistance," we specifically considered the accelerated aging method of adjusting the CO content of the fuel to change the degree of degradation. However, we could not obtain the expected results within several thousand hours, and therefore, it is as written in the paper.

\section{Standardization of the accelerated aging test of the polymer electrolyte fuel cell}

Question(Norimitsu Murayama)

Is the introduced gas switching test standardized? Answer (Kazumi Tanimoto)

To be established as the actual accelerated test protocol, I think it is necessary to calculate the acceleration coefficient by comparing the developed accelerated test protocol with the tests conducted under standard conditions. Since there are not many tests conducted in real time, it is necessary to collect sufficient data including the text conducted by the accelerated aging method. 